\title{
A semi-analytical method to evaluate the J-R curve for the surface-cracked round bar under three-point bending
}

\author{
Guangwei $\mathrm{He}^{1}$, Lixun $\mathrm{CAI}^{1}$, Chen $\mathrm{Bao}^{1}$, and Xudong Qian ${ }^{2}$ \\ ${ }^{1}$ Southwest Jiaotong University School of Mechanics and Engineering \\ ${ }^{2}$ National University of Singapore Department of Civil and Environmental Engineering
}

October 2, 2021

\begin{abstract}
The current paper presents a semi-analytical method for obtaining $J$-R curves of round bars with elliptical cracks. This method derives the semi-analytical expressions between load and displacement, $J$-integral and displacement for surface-cracked round bars, based on the energy density equivalence principle, taking into account the effect of material and crack size. The validity of semi-analytical expressions examined by three-dimensional finite element analysis shows that load displacement curves and $J$-integral ${ }^{\sim}$ load curves predicted by the expressions match well with the simulation results. Through fracture toughness testing conducted on the carbon steel 45 , the load $\sim$ displacement data are used to calculate the average $J$-R curves for the surfacecracked round bar by the semi-analytical expressions. With the distributions of $J$-integral along the crack front obtained from three-dimensional finite element analyses, this study also determines the $J$-R curves at different crack-front points.
\end{abstract}

\section{Hosted file}

manuscript20210924.docx available at https://authorea.com/users/439031/articles/540086a-semi-analytical-method-to-evaluate-the-j-r-curve-for-the-surface-cracked-round-barunder-three-point-bending 